Researching public library programs through Facebook events

\title{
a new research approach
}

Mathiasson, Mia Høj; Jochumsen, Henrik

Published in:

Journal of Documentation (JDOC)

DOI:

10.1108/JD-08-2018-0137

Publication date:

2019

Document version

Peer reviewed version

Citation for published version (APA):

Mathiasson, M. H., \& Jochumsen, H. (2019). Researching public library programs through Facebook events: a new research approach. Journal of Documentation (JDOC), 75(4), 857-875. https://doi.org/10.1108/JD-08-20180137 


\title{
Researching public library programs through Facebook events: a new research approach
}

\begin{abstract}
Purpose - This paper reports on a new approach for researching public library programs through Facebook events. The term public library programs refers to publicly announced activities and events taking place within or in relation to a public library. In Denmark, programs are an important part of the practices of public libraries and have been growing in both number and variety within recent years.

Design/methodology/approach - The data for the study presented in this paper consists of Facebook events announcing public library programs. In the study of this data, grounded theory is used as a research strategy and methods of web archiving are used for collecting both the textual and the visual content of the Facebook events.

Findings - The combination of Facebook events as data, grounded theory as a research strategy and web archiving as methods for data collection proves to be useful for researching the format and content of public library programs, which have already taken place.

Research limitations/implications - Only a limited number of Facebook events are examined and the context is restricted to one country.

Originality/value - This paper presents a promising approach for researching public library programs through social media content and provides new insights into both methods and data as well as the phenomenon investigated. Thereby, this paper contributes to a conception of an underdeveloped researched area as well as a new approach for studying it.
\end{abstract}

Keywords Public libraries, Public library programs, Social media content, Facebook events, Grounded theory, Web archiving, Research methods

Paper type Research paper

\section{Introduction}

Since their early years, public libraries have been engaged in arranging and hosting programs as part of their practices. In the US, the tradition of public library programming dates back to the late 1880s (Lenstra, 2018) and today, the number and variety of public library programs offered is immense. As an example, the New York Public Library offers more than 93,000 programs annually, serving "everyone from toddlers to teens to seniors" (New York Public Library, 2018). In Denmark as well as in the US, programs have been a part of the practices of public libraries for many years and increasingly since the middle of the 1960s (Thorsen, 1992). According to the annual national assessment reports on public libraries, within recent years, the programs offered by Danish public libraries have grown in both quantity and variety. From 2010 until 2015, the number of categories used to survey and assess public library programs more than doubled: from 15 categories in 2010 to 34 categories in 2015 (Danish Agency for Culture and Palaces, 2010; 2015). However, regardless of 
adjustments and additions, the existing categories used to survey and assess public library programs appear to be too narrow and fail to grasp the complex variety of programs offered. This problem seems symptomatic for the fact that little is known about public library programs and that research on this phenomenon as a unified area of study is limited. What is in fact a public library program? A recent example of an attempt to define public library programs, can be found in the research project National Impact of Library Public Programs Assessment (NILPPA). According to the NILPPA research project, the problem of defining public library programs relates to the need of a general conception of this phenomenon. Considering the lack of a general conception of public library programs and looking back at the Danish situation, where the seemingly diverse and complex variation of programs proliferate the existing categories used to survey and assess them, it becomes clear, that more research is needed in order to define, assess and discuss public library programs in the future. However, before developing any definitions, and engaging in assessments and discussions, what is needed is an approach for researching public library programs. How to research public library programs as a unified area of study? The aim of this paper is to present an answer to the question of how to research public library programs by reporting on a new research approach for doing so.

By the term public library programs, this paper refers to publicly announced activities and events, taking place within or in relation to a public library. Furthermore, public library programs are social interactions in which library professionals and members of the community are involved. This definition stresses the importance of the public announcements. Many libraries announce their programs on their website and, additionally, on social media sites such as Facebook. In Denmark, more than $90 \%$ of public libraries use Facebook as a platform for communicating with their users (Danish Agency for Culture and Palaces, 2015) and the announcement of programs is a central feature here. This is one of the reasons why the data for this study consists of Facebook events announcing public library programs, found and collected from public library Facebook pages. The strategies for data collection, data analysis and theory development presented are based on these writings on grounded theory. Combining writings on grounded theory as formulated by sociologists Anselm Strauss and Juliet Corbin (1990; 2008) and sociologist Kathy Charmaz (2006; 2014) the content of the Facebook events are analyzed and coded. Furthermore, methods of web archiving are applied for collecting and preserving the Facebook events.

The questions raised in this paper are: What characterize Facebook events as data? How can grounded theory be applied to the study of Facebook events? And how are methods of web archiving contributing to this study? As these questions are answered, new questions will be raised from reflecting on the approach. Ultimately, the research question is whether the combination of Facebook events as data, grounded theory as research strategy and web archiving as methods for data collection make up a valuable research approach, for studying public library programs in a digital age?

\section{Literature review}


In the following, existing writings on public library programs are introduced. Then follows an introduction to studies of public libraries and their use of social media, especially Facebook. Finally, different methods for studying Facebook content are presented in relation to libraries and beyond.

\section{Literature on public library programs}

As a topic, public library programs is an under-developed research area. However, historical writings have addressed this topic. Looking at especially American and British literature, writings on public library programs can be found dating back to the 1920s, though at that time, they were not termed "programs". Going through some of the early writings on "extension work" (McColvin, 1927; Leyland, 1938) and "extension activities" (Baguley, 1959; Jolliffe, 1962), public library programs are framed as something extending or augmenting the library and its services and broadening up its user base. Thus, public library programs have historically been used as part of library publicity. Around the same time, programs were closely associated with "educational activities" (Sydney et al., 1950; Smith, 1954; Stevenson, 1963) promoting literacy through the access to books. The American library researcher David W. Davies draws the distinction between "book activities" and "non-book activities" (Davies, 1974, p. 1), emphasizing a divide between what has to do with the traditional idea of library collections and what has not. However open this division might seem, the "non-book activities" were still justified "on the grounds that they stimulated reading" (Davies, 1974, p. 61). The justification to stimulate reading - or more broadly - to stimulate the use of and commitment to culture is found in the term "cultural activities", which has been widely used in Europe, especially in the UK, since the 1960s (Department of Education and Science, 1975). The more neutral term "library programs" origins in the 1970s (LaFleur and Robotham, 1976; 1981). By the phrase "library program", staff members at the New York Public Library, Lydia LaFleur and John S. Robotham, refer to "any activity, in or out of the library, in which a librarian and two or more members of the public are involved" (LaFleur and Robotham, 1981, p. ix). Importantly, library programs were considered as public services, which should be equally available and accessible for all.

What these early writings have in common, is the fact that they are written by librarians with experience in planning and conducting public library programs. In recent research-based literature on public library programs, instead of focusing on the broad conception of the phenomenon the researchers often focus on specific types of public programs and their roles and functions. Examples include research on literacy promoting programs (Hedemark, 2017; Goulding et al., 2018; Hedemark and Lindberg, 2018), creative programs (Noh, 2017), conversation-based programs (Johnston, 2018; Johnston and Audunson, 2019) and health promoting programs (Rubenstein, 2016; Lenstra, 2017, 2018; Luo, 2018). Another tendency is the focus on specific groups of library users such as families (Lopez et al., 2017), young people (Rockefeller, 2008) and immigrants (Audunson, 2005; Vårheim, 2014; Johnston and Audunson, 2017). Thus, recent research rarely addresses public library programs as a whole, but tends to focus on specific types of programs, specific outcomes or specific groups of user. Acknowledging the existing research as well as the early experienced-based writings, this research paper wishes to qualify the broad conception of what a public library program is by presenting an approach for researching public library programs as a unified area of study. 


\section{Social media and Facebook in relation to public libraries}

Concurrent with the rising interest into the "Library 2.0", from 2007 onwards, a growing body of research on the use of social media in public libraries has emerged (Carlsson, 2015). LIS research on social media and public libraries has investigated aspects such as content, the perceptions of stakeholders and strategies for social media use (Joo et al., 2018). Several researchers have explored the best practices for effective deployment and use of social media in public libraries (Cahill, 2011; Tomlin, 2014), including the way in which libraries advertise their services through Facebook (Chen et al., 2012; Aharony, 2012; Madge and Coserea, 2014). Today, Facebook is one of the most heavily used social media platform in the library community (Joo et al., 2018). In the US, libraries have been using Facebook to communicate with their patrons and, particularly, for promoting their activities, programs and services. In 2012, more than $80 \%$ of the larger public libraries in the US had a Facebook page, and 93\% of the biggest libraries had one (Hofschire and Wanucha, 2014). In Denmark as well, besides the library websites, Facebook is the most used online platform for promoting library programs.

\section{Methods for studying Facebook content}

In a study from 2012, library researcher Noa Aharony compares the use of Facebook in American public and academic libraries concentrating on the content of Facebook wall posts (Aharony, 2012). Aharony aims to describe and classify the Facebook use. The analysis consist of both statistical descriptive analysis and content analysis. Aharony finds, that both kinds of libraries use Facebook and Facebook wall posts "simply as a way to deliver information to users, rather than as a venue for discussion" (Aharony, 2012, p. 366). This is an important finding that supports the reason to study the content of the information delivered by the libraries and the library professionals, rather than the (limited) discussions or conversations between the libraries and their users. In a recent study, library researcher Soohyoung Joo and colleagues explore the different kinds of social media content created public libraries (Joo et al., 2018). Their primary focus is on what types of content public libraries post on Facebook. However, the type of content discussed consists of Facebook wall posts and not Facebook events. Interestingly, this study uses a mixed-method approach that includes grounded theory coding inspired by Strauss and Corbin (1990). The study affirms that the most common type of content posted by public libraries on Facebook concerns library programs, including both coming library programs (upcoming event announcements) and past library programs (completed events). This type of content makes up almost half of the observed posts (Joo et al., 2018). Both studies conclude that Facebook is mainly used by libraries as a way to deliver information to their users and this information most often concerns their programs and events. Thus, public library Facebook event pages can be seen as archives of information about not only programs to come but also programs of the past.

Outside of the LIS field, qualitative studies have been done on different types of Facebook content, including Facebook wall posts and Facebook events. In a study conducted by researchers Nadar Afzalan and Jennifer Evans-Cowley, Facebook wall posts are explored as part of an investigation of social media sites as platforms for urban planning at a neighbourhood scale. The study looked at three Facebook neighbourhood groups to explore the usefulness of such online forums. Part of their study 
builds on content analysis methods for studying the member's posts. These were classified according to four main categories: 1) asking for help, 2) informing other members about activities, 3) expressing personal experiences and 4) selling, buying or renting (Afzalan and Evans-Cowley, 2015). In another study from 2010, business and finance scholars Zuhair Khan and Sirkka Jarvenpaa examine 294 Facebook events to understand how social groups use the event pages to organize events and resolve problems (Khan and Jarvenpaa, 2010). Both of these examples show, that existing studies on the content of Facebook wall posts and Facebook events tend to focus on different types of communicative interactions and often take form as content- or discourse analyses. With this in mind, the research approach presented in this paper differs from social media research focusing on Facebook as a social network site for personal- or interpersonal communication. What is central in this paper is the one-to-many-communication information provided by library professionals in the form of Facebook events announcing public library programs. Thus, it adds to the existing LIS research about Facebook use in public libraries by analyzing the Facebook content as data representing intended public library programs. As sources of data for a grounded theory study, Facebook events and Facebook event descriptions are relatively unexplored. Therefore, an introduction to what characterizes this data is needed.

\section{Introducing the data}

Why use Facebook events as data for researching public library programs? There are several reasons for looking at Facebook content, when studying public libraries and their programs. One of them is the fact that "social media has transformed the ways organizations reach out to the public" (Carpenter and Lertpratchya, 2016: 449). This also concerns public libraries and their communication practices. Social media sites such as Facebook enable libraries to efficiently promote their services, programs and events online to their communities (Joo et al., 2018). As public announcements, the Facebook events are products made to serve a specific purpose, i.e. as part of the PR-activities. The writers of these texts are librarians or library professionals. When describing intended public library programs, the writers provide rich data about both format and content of these programs. Facebook events share several characteristics relating to format and content. These characteristics are, to a certain degree, structured by the design and interface of the platform. Figure 1 illustrates the specific part of the Facebook event pages of interest to this study as well as the elements, which make up a Facebook event. The Facebook events all include a title and often an image, information about location, time and date as well as the organizer(s) of the event. All of this information relate to the format of public library programs. By the term Facebook event descriptions, this paper refers to the texts found within the fields called "Details". Here, descriptive texts of varying length provide information about the content of the programs announced as well as the practical circumstances behind them. 


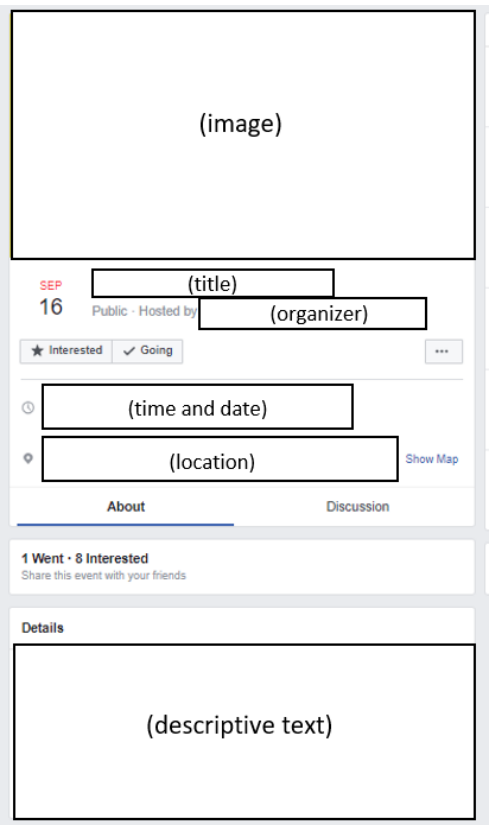

Figure 1. Illustration of the elements, which make up a Facebook event.

\section{Research design and -processes}

Drawing on writings by Strauss and Corbin $(1990 ; 2008)$ and Charmaz $(2006 ; 2014)$, the research approach presented in this paper is based on the methodological and theoretical underpinnings of grounded theory, which subsequently influence the overall research design and processes. The use of texts in a grounded theory study can serve multiple purposes and stimulate "theoretical sensitivity" (Strauss and Corbin, 1990: 50) by providing concepts and relationships that are then related to the data. But texts can also be used "as objects for analytic scrutiny themselves" (Charmaz, 2006: 39). Particularly useful for this paper, is the distinction between extant and elicited texts described by Charmaz, which makes it possible to use texts as the primary sources of data for a grounded theory study. Extant texts "consist of varied documents that the researcher had no hand in shaping" (Charmaz, 2006: 35). Among other things, extant texts are public records, government reports, organizational documents, mass media, personal correspondence and Internet discussions. Elicited texts are texts, which involves the researcher as means of gathering data e.g. memos or field notes. In this paper, the Facebook event descriptions are considered as extant texts. In relation to the main function of announcing public library programs, these texts can be said to mutually constitute and define "the observed world" (Charmaz, 2006: 38). By looking at the archive of "Past events", it becomes possible to research public library programs, which have already taken place. Thus, using the pages and profiles that constitute social media as texts for analysis (Robards and Lincoln, 2017), this paper presents a qualitative analysis of Facebook event descriptions as extant texts.

Characteristic of grounded theory is a reciprocal relationship between data collection, data analysis and theory development (Strauss and Corbin, 1990). This means that research carried out using grounded theory does not limit itself to collecting and analyzing data in order to verify a preexistent hypothesis, but instead it "aims at using the initial data as a starting point in order to construct in a 
creative way an explanation of the phenomena investigated" (Faggiolani 2011, 2, emphasis added). A core process in the construction of the phenomenon investigated is coding. In grounded theory, the term coding is used synonymous with analysis, meaning that the processes of coding are essentially analytical.

"Coding is the pivotal link between collecting data and developing an emergent theory to explain these data. Through coding, you define what is happening in the data and begin to grapple with what it means" (Charmaz, 2006: 46, original emphasis).

Charmaz operates with at least two stages of the coding process: initial coding and focused coding (2006; 2014). These stages share several similarities with what Strauss and Corbin term open coding and selective coding (1990). By combining the four coding procedures, this paper reports on how they complement and supplement each other. During the data collection and coding processes, elicited texts in the form of memos are written and diagrams are made as important "records of analysis" (Corbin and Strauss, 2008: 117). The research design and -processes are illustrated as three steps referring to data collection, data analysis and theory development (Figure 2). During all research processes, memos are written and diagrams are made to reflect on findings and ideas generated. After each step, the memos are compiled and numbered in order to inform the further analysis and theory development.

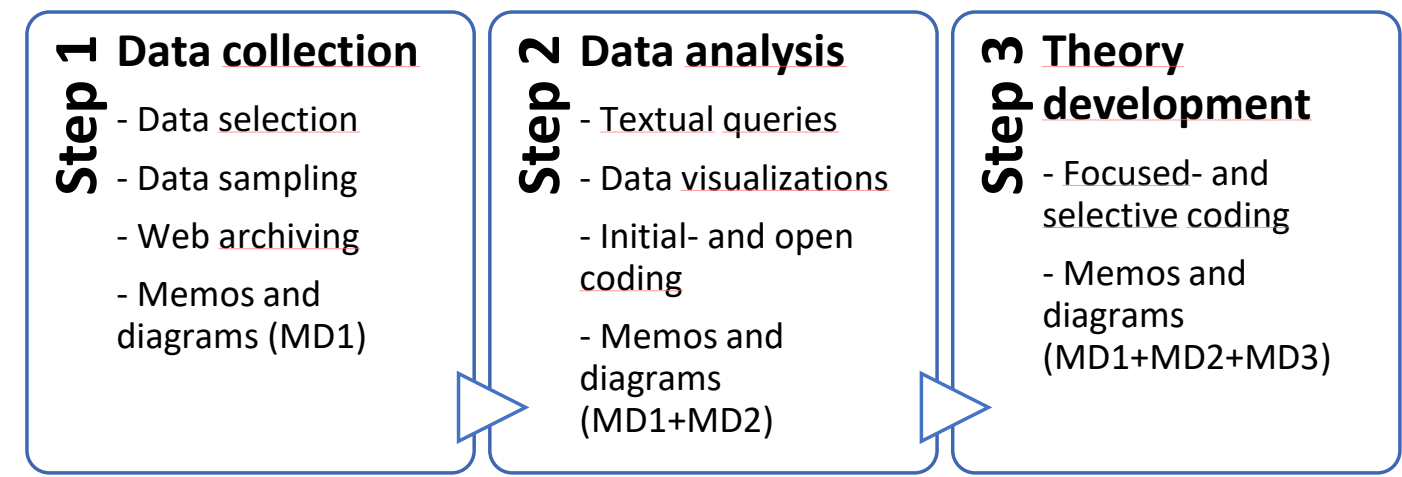

Figure 2. Diagram of the research design illustrated as a three-step-process referring to data collection, data analysis and theory development.

The three-step-process has inspired the structure of the following parts of this paper. Thus, the first section reports on the process of data collection by use of web archiving, including the criteria behind data selection and the procedures behind data sampling. The second section reports on data analysis through textual queries and data visualizations as well as the procedures of initial- and open coding, in which categories and subcategories are discovered. Building on these categories and subcategories, in the third section, focused- and selective coding procedures are used to inform the development of a grounded theory of public library programs by exploring what might be the core categories. Explaining each of the research processes step-by-step serves a pedagogical purpose, however, it does not correspond to the reciprocal way this study has in fact been conducted. 


\section{Data collection}

In the following, the criteria behind data selection and the methods for data sampling and data collection are introduced.

\section{Criteria behind data selection}

In a grounded theory study, the primary sources of data should be chosen to ensure quality. According to Charmaz, this means that the data must be "rich", hence "detailed, focused, and full" (Charmaz, 2006: 14). Other important criteria behind the data selection for a grounded theory study are usefulness, suitability and sufficiency. The data should be useful for developing core categories and suitable as well as sufficient for depicting empirical events (Charmaz, 2006). Thus, a criteria behind choosing Facebook events as the primary sources of data is the fact that these texts are descriptive and detailed, hence, they provide what Charmaz calls rich data. Furthermore, as extant texts and rich data, the Facebook event descriptions are useful for developing core categories. The fact that more than $90 \%$ of Danish public libraries use Facebook as one of their main platforms for promoting and announcing programs makes the data sufficient. In the archives of "Past events", event descriptions dating as far back as 2011 are found. This is not the case when consulting event calendars on public library websites. Also, when using Facebook as a platform for announcing programs, the announcements become more alike, hence more comparable and suitable for research.

\section{Data sampling procedures}

Inspired by a mixed method approach for data sampling, this study aims for a diverse sample of public library Facebook pages by using both probability sampling to increase external validity and purposive sampling to increase transferability (Teddlie and $\mathrm{Yu}, 2007: 78$ ). In order to choose the Facebook pages from which to collect data, this paper looks at the Danish municipalities as an overall sample. In Denmark, there are 98 municipalities belonging to five different regions. The municipalities are considered local authorities in charge of administering numerous public institutions, including public libraries. Wanting both quantity - to secure sufficiency - and quality - to secure usefulness and suitability - the procedures for data sampling both focus on generating representative samples and information rich cases. Since most municipalities make use of one collective Facebook page for their entire library system, the municipalities function as a representative sample of the library systems. To narrow down the overall sample of 98 municipalities/library systems, a stratified purposive sampling procedure is applied. "The stratified nature of this sampling procedure is characteristic of probability sampling, whereas the small number of cases typically generated through it is characteristic of purposive sampling" (Teddlie and Yu, 2007: 90). Following this technique, the overall sample is divided into different strata and then a small number of cases within each strata are selected for closer inspection. First, the 98 municipalities/library systems are divided into strata by classifying them according to the four municipality types urban, medium, rural and peripheral, referring to the number of inhabitants and the concentration of cities versus rural areas within the municipalities. The different types of municipalities are considered one strata. Then, using national statistics made by the Ministry of Economic Affairs and the Interior ${ }^{[1]}$, searches are made for each of the four municipality types focusing on one criteria: public library expenses per citizen. The search results are used to classify the municipalities/library systems according to three subcategories of 
library budgets; above average, average and below average. These three subcategories are considered another strata. Finally, from each of the four municipality types, the three municipalities with the lowest expenses, the highest expenses and the expenses closest to average are selected. In this selection, the overall sample of 98 is narrowed down to a sample of 36 municipalities/library systems varying according to municipality type and budget. Then follows a purposive sampling of a small number of cases within each strata to provide a diverse body of data. In addition to municipality type and budget, geographical location and the size of the library system are added as criteria behind the purposive sampling. Furthermore, a main criterion for this study is of course the use of Facebook to announce programs. The libraries' use of Facebook as a site for announcing programs should date back to at least 2015, preferable longer. Finally, wanting the sample to reflect a broad variety of usages, the number of event descriptions found under "Past Events" are listed as the sixth criterion. The six sampling criteria are:

1. Size (referring to the number of public libraries within the library system)

2. Library budget pr. citizen

3. Geographical location

4. Municipality type

5. Facebook used since (at least 2015)

6. Number of event descriptions (at the time of data collection)

From the sample of 36 municipalities, 12 Facebook pages are selected representing 12 municipalities/library systems and no less than 48 public libraries (Table 1). The selected cases all vary in relation to the six sampling criteria and, thus, they reflect both depth and breadth. The cases vary according to budget, geographical location and municipality type. There is a great variety in the use of Facebook. Some cases have been using Facebook for announcing and promoting programs since 2011, other cases start using Facebook for announcing and promoting programs in 2015. Some have been using Facebook frequently, others have been inactive for rather long periods. This means that the number of Facebook events per case vary from eight to 586.

\begin{tabular}{|c|c|c|c|c|c|}
\hline Size & Budget & Geographical location & Municipality type & Facebook used since & $\begin{array}{c}\text { Number of event } \\
\text { descriptions }\end{array}$ \\
\hline 2 & above & Capital Region & Urban municipality & January 2013 & 586 \\
\hline 3 & average & Capital Region & Urban municipality & June 2011 & 195 \\
\hline 4 & below & Central Jutland & Urban municipality & August 2011 & 106 \\
\hline 2 & above & Capital Region & Medium municipality & January 2014 & 99 \\
\hline 5 & average & Zealand Region & Medium municipality & October 2014 & 138 \\
\hline 4 & below & Central Jutland & Medium municipality & January 2011 & 319 \\
\hline 7 & above & Zealand Region & Rural municipality & January 2011 & 548 \\
\hline 5 & average & Northern Jutland & Rural municipality & August 2015 & 168 \\
\hline 3 & below & Southern Denmark & Rural municipality & September 2014 & 8 \\
\hline 5 & above & Southern Denmark & Peripheral municipalities & September 2012 & 337 \\
\hline 5 & average & Southern Denmark & Peripheral municipalities & February 2012 & 119 \\
\hline 3 & average & Northern Jutland & Peripheral municipalities & March 2013 & 83 \\
\hline
\end{tabular}

Table 1. Overview of the selected cases. 


\section{Data collection through web archiving}

In order to collect and preserve the Facebook events for research, this study uses methods of web archiving. Web archiving entails methods for collecting, fixating and documenting online data for qualitative research (Lomborg, 2012). The type of web archiving conducted in this study can be characterized as "micro archiving" (Brügger, 2005), which is adjusted to fit the research design. Basic reasons for archiving web material are the need for a stable research object, the need for documentation and the need for illustration (Sandvik, et al., 2013). Internet content such as Facebook events are characterized as "ephemera" (Charmaz, 2006: 50) and as a research object, it needs to be stabilized. Further, in order to secure transparency and reliability, there is a need for documenting and illustrating the object of study. These are the reasons why, in this study, methods of web archiving are used to collect, fixate and document both the visual representations of the Facebook events as well as the textual data and metadata connected to them. In order to collect and preserve the visual representation of the Facebook events, a "screen capture" (Brügger, 2011) or "still image" (Sandvik, et al., 2013) method is used, which basically entails taking a screenshot of a selected part of the screen for preservation. Thus, this type of web archiving both stabilizes the research object and contributes to documentation and illustration. For now, this method is termed the screen capture method. "A screen capture looks exactly like what you see when you look at the website (without interacting with it), i.e. with all the textual and static elements and layout preserved" (Nielsen, 2016: 43). The reason for using the screen capture method is to collect and preserve a still image of a selected part of the screen - the part of the Facebook event pages illustrated in Figure 1. To collect this data, the screen capture software Snagit2018 ${ }^{[2]}$ is used, since it enables the researcher to capture only a selected part of the screen. The Facebook events are found by clicking the "Events" link on the library Facebook home page. On the "Event page", both "Upcoming Events" and "Past Events" are found. For the purpose of this study, the "Past Events" are seen as rich archives representing library programs, which have already taken place. Using the "scroll back method" as a way to "look back in time" on Facebook (Robards and Lincoln, 2017), the process of screen capturing is conducted one event at a time. The screenshots are collected chronologically by case and preserved. As snapshots of social media content, the screen capture method implies a time-specific insight into "a certain portion of the web at a certain point in time" (Brügger, 2011: 28). The screenshots preserve and document the visual content of the Facebook events such as text and images as well as the structural and graphical layout. During the process of screen capturing, memos are written, which reflect both thoughts and ideas about the content of the data and the utility of this method. One of the limitations of the screen capture method is that it does not preserve any dynamic content, sound or moving images (Nielsen, 2016). However, since sound and moving images are rarely found among the Facebook events (this study reports on one out of 2785), this limitation is not considered a problem.

For collecting, fixating and documenting the textual data and metadata connected to the 2785 Facebook events, a method called "harvesting via API" (Sandvik, et al., 2013) is used. The advantages of the harvesting via API method are the possibility for capturing the entire textual content of a page. Furthermore, a great advantage of this method is the fact that the data collected is machine-readable, which means that it is "searchable, clickable and sortable" (Sandvik, et al., 2013: 16) for further analysis. The disadvantages of the harvesting via API method include the lack of possibility for 
capturing the original visual representations (Sandvik, et al., 2013), which is why in this study, the screen capture method is used complementary. As a tool for harvesting textual data via API, a lowlevel HTTP-based API called "Graph API" is used. "Graph API" is offered by Facebook on the website "facebook for developers" and is a tool for getting data into and out of Facebook. This tool can be used to programmatically query data from the platform. ${ }^{[3]}$ The Graph API is composed of nodes (individual objects such as a user, a page, or a comment), edges (connections between a collection of objects and a single object, such as photos on a page or comments on a photo), and fields (data about an object, such as a user's birthday, or a page's name). ${ }^{[4]}$

In this study, fields are used to specify the information wanted by typing the names of the library Facebook pages and choosing to collect all "Past events" available up until December 31, 2017. Requesting the name of the event, start- and end time, location as well as the event descriptions from the "Details" field, the textual data is collected from one library Facebook page at a time. The collected data is saved as JSON files and exported to Excel, where it is organized according to title, event description, location, time and date. Further, each individual case is identified by an index number, resulting in a database consisting of textual data and metadata of 2785 Facebook events dating back to January 2011. In Figure 3, the yearly distribution of the collected data is illustrated. Many Danish libraries start using Facebook later than 2011 and the use gradually increases. Especially the period from 2015 to 2017 is well represented in the data. It is important to bear in mind that this data does not correspond to the actual number of programs, which have been taking place but only to the number of programs, which have been announced on Facebook and were available at the time of data collection. ${ }^{5}$

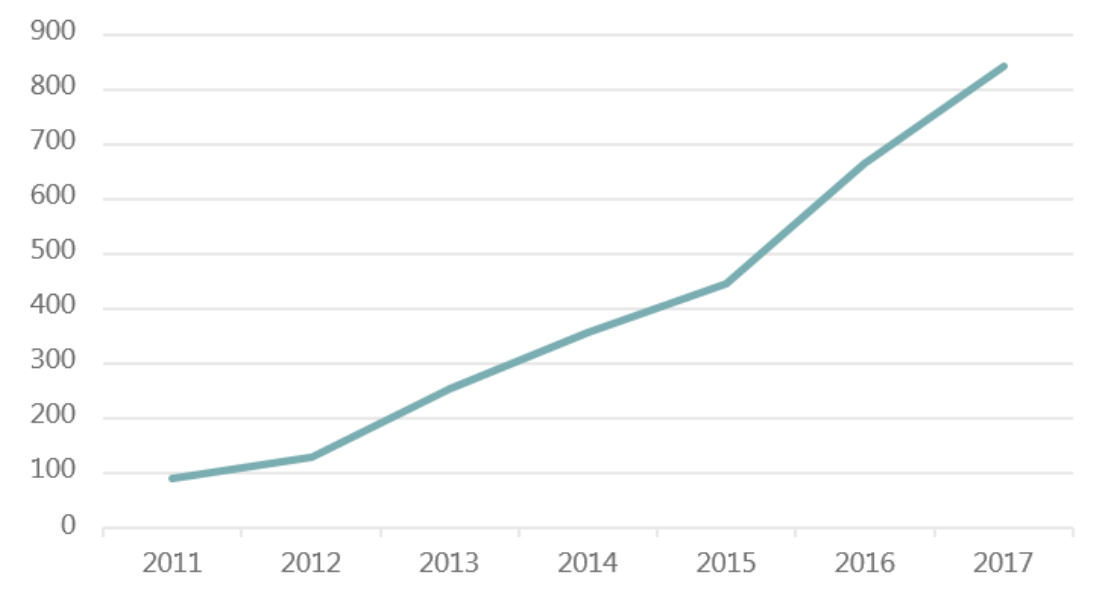

Figure 3. Overview of the yearly distribution of the Facebook events collected.

\section{Data analysis}

The analysis of data is an extensive task in any grounded theory study and it cannot be separated from the processes of data collection and theory development. Therefore, the analysis will be drawing on memos from the data collection process as well as pointing at preliminary findings related to the development of a grounded theory of public library programs. Since the aim of this paper is to present 
the research approach, the findings reported in this paper are mainly included as examples to illustrate the different coding processes.

\section{Data queries and visualizations}

The Excel sheets with textual data from Facebook are combined and imported into the qualitative data handling software NVivo for the analysis. As a first step to explore the data, a Word Frequency Query (WFQ) is conducted. This step is an important part of the analysis in at least two ways; it helps gaining an overview of the 2785 individual Facebook events; and it informs the writing of new memos and the generation of ideas for the coding processes. Once the words are summarized in a WFQ and sorted by occurrence, the data is cleaned to identify and remove all stop words by adding them to a stop words list. Stop words are common words that does not contribute to the content of the information being conveyed (Silver and Matthews, 2017). Examples of such stop words include "that", "I", "it", "why", "therefore" and "or". An interesting finding from the WFQ is that the three words most often used are free, ticket and registration. These words are all referring to access, which seems to be a key category behind public library programs. Important to notice is also that the most used words are in fact not used that frequently. Looking beyond the "top 3", the words appears around 700-500 times and beyond the "top 10" around 250 times or less. This finding indicates that public library programs are described in very different ways and that the same types of programs might be found behind a variety of different titles and descriptions.

Experimenting with data visualization at an early stage of the analysis, is an important part of getting to know the data. In this study, the data visualization software Tableau ${ }^{[6]}$ is used. One of the result from the early experiments, is a color scheme (Figure 4) illustrating all 2785 Facebook event titles as circles in varying sizes and colors. Darker and bigger circles indicate matching titles. Not many Facebook events share the same title; the biggest and darkest circle refer to only 35 events. The visualization of the data as a pool of individual circles supports the finding from the WFQ comparing the titles of Facebook events provide no real insights into the content of the public library programs announced. Hence, a throughout exploration of the Facebook event descriptions is needed in order to detect key concepts and categories. This is essentially what the processes of grounded theory coding is all about. In the following, a combination of initial coding as explained by Charmaz (2006; 2014) and open coding as explained by Strauss and Corbin (1990; 2008) is used to explore concepts and categories found in the Facebook event descriptions. 


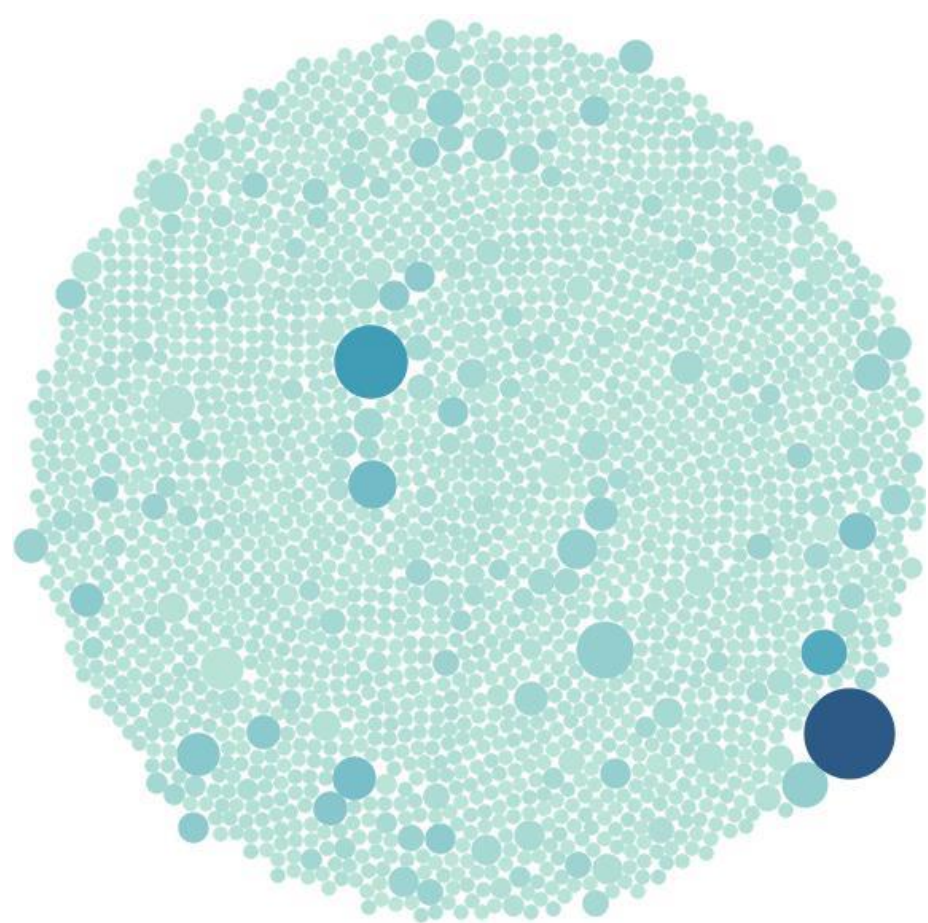

Figure 4. Data visualization as a color scheme illustrating the titles of all 2785 Facebook events as circles.

\section{Initial- and open coding}

Initial coding signifies the study of "fragments of data - words, lines, segments, and incidents closely for their analytical import" (Charmaz 2006: 42). In order to conduct a throughout initial coding, a smaller sample of 278 randomly selected Facebook events corresponding statistically to the yearly distribution of the data was made. This sample was then divided into two samples of 139 Facebook events each, for experimenting with two types of initial coding techniques explained by Charmaz: word-by-word and line-by-line coding. The word-by-word coding technique is particularly helpful when working with certain types of "ephemera" (Charmaz 2006: 50), such as Internet data. During the word-by-word coding, researchers "may attend to the structure and flow of words, and how both affect the sense you make of them, as well as their specific content" (Charmaz 2006: 50). A result from the word-by-word coding, is that a broad variety of themes and topics are covered by many different types of programs. An overall reflection concerning the variety of themes and topics found, is that no topic appears to be too big or too small. Other important outcomes of the word-byword coding include code nodes such as access, partners and collaboration, actors and agents, the role of the library professionals, the role of the participants and location.

The line-by-line coding technique is used to code the remaining 139 event descriptions from the sample. As the name of this technique implies, it involves the coding of every line, even though "this may seem like an arbitrary exercise because not every line contains a complete sentence and not every sentence may appear to be important (...)" (Charmaz, 2006: 50). In grounded theory research, asking questions is a central part of all coding procedures. Asking questions help creating an overview of the types of programs as well as the different elements related to them. All of these elements are important for the development of a theory grounded in the area of study. Basic questions are what, 
where, when, who, how and why. There are also more complex questions and these questions comes from the data (Charmaz, 2006). Line-by-line coding can be an enormously useful tool for generating ideas and posing questions about the data and of the data (Strauss and Corbin, 1990). In the coding of every line of the Facebook event descriptions, the basic questions posed are what, where, when, who, how and why. Questions about the data address the texts and the structure of the Facebook events and event descriptions, whereas questions of the data address the format, content and function of the programs described. Thus, depending on the object of the question, the basic questions provide different answers. In Table 2, the difference between asking questions about the data and of the data is illustrated and the answers provided by the line-by-line coding are reported. Summing up, line-byline coding appears to be useful for understanding the structural aspects of the Facebook events and for answering basic questions about and of the data.

\begin{tabular}{|c|c|c|}
\hline $\begin{array}{l}\text { Basic } \\
\text { questions }\end{array}$ & ... about the data (as texts) & $\begin{array}{l}\text {...of the data (as descriptions of public library } \\
\text { programs) }\end{array}$ \\
\hline What? & Textual data in a graphical layout & Information about the content \\
\hline Where? & Public library Facebook pages & The location of the programs announced \\
\hline When? & $\begin{array}{l}\text { Published between January } 2011 \text { and } \\
\text { December } 2017\end{array}$ & The duration of the programs announced \\
\hline Who? & Written by librarians or library professional & $\begin{array}{l}\text { Information about the organizers and the intended } \\
\text { participants }\end{array}$ \\
\hline How? & $\begin{array}{l}\text { Announcements consisting of fixed fields } \\
\text { and free fields }\end{array}$ & $\begin{array}{l}\text { Information about practical circumstances such as } \\
\text { entrance fees, registration or preparation }\end{array}$ \\
\hline Why? & $\begin{array}{l}\text { To promote and announce coming events } \\
\text { and reach a broad audience }\end{array}$ & $\begin{array}{l}\text { The function of the programs can, to some extent, } \\
\text { be interpreted from the descriptions (e.g. in the } \\
\text { "sales pitch") }\end{array}$ \\
\hline
\end{tabular}

Table 2. Illustration of the difference between asking questions about the data and $o f$ the data.

\section{Open coding}

According to Strauss and Corbin (1990), open coding is defined as the process of breaking down, examining, comparing, conceptualizing and categorizing data. In this process, researchers are qualifying concepts and categories, hence, ascribing them with meaning (Corbin and Strauss, 2008). A characteristic aspect of open coding, is the fracturing of data in order to identify categories, properties, and dimensional locations (Strauss and Corbin, 1990). Categories are "higher-level concepts under which analysts group lower-level concepts according to shared properties" (Corbin and Strauss, 2008: 159). Attributes or elements characteristics to a category are called properties. Dimensions are defined as "variations within properties that give specificity and range to concepts" (Corbin and Strauss, 2008). Hence, dimensional locations refer to the idea of locating the properties of a category on a continuum of variations. Thinking about the relationship between categories, properties and dimensional locations is useful for finding similarities and patterns in the data. In the process of open coding, findings from the WFQ and the initial coding are analyzed by identifying categories, properties and dimensional locations in the smaller sample of data. Analyzing the categories in relation to their properties and dimensional locations, some categories suggests 
themselves while others are more challenging. A category that suggests itself is access. The three words appearing most frequently in the data - free, ticket and registration - can all be said to define or describe elements referring to access as a category. These words can be identified as the properties of access. Additional properties of access are price, skills or preparation needed. As illustrated in Figure 5, the properties of access can be located on a continuum of variations oscillating between two extremes: from programs with free entrance that are "open for all" to programs with entrance fees and limited access. In between these poles are multiple other combinations, which should be explored further.

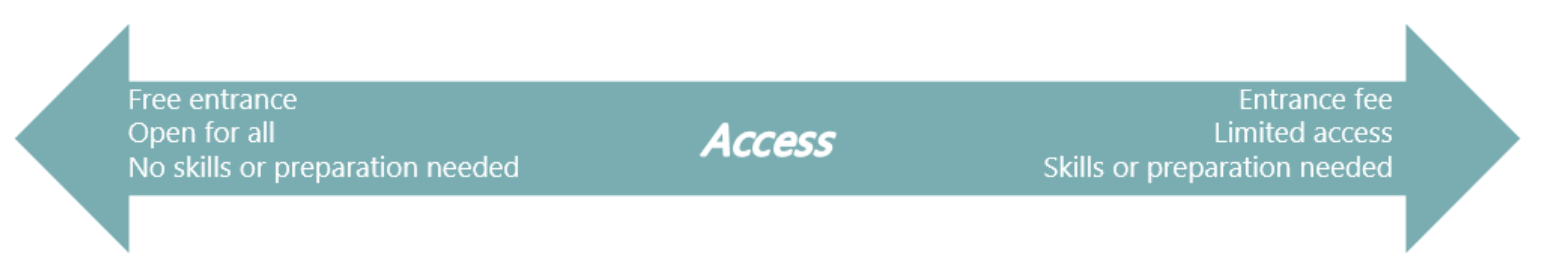

Figure 5. Access continuum.

\section{Theory development}

In the focused- and selective coding, what seem to be the most useful findings from the initial and open coding of the smaller samples are tested and validated against the extensive data to develop what will become a grounded theory of public library programs.

\section{Focused coding}

The large amount of Facebook events collected in this study provides a quantitative aspect and allows for testing and validating the findings against a bigger body of data. In focused coding, researchers select what seems to be the most useful, significant or frequent earlier codes and test them against extensive data to "synthesize, analyze, and conceptualize larger segments of data" (Charmaz, 2014: 138). Thus, focused coding "requires decisions about which initial codes make the most analytic sense to categorize your data" (Charmaz, 2014: 138). Some of the most interesting initial codes includes access, the role of the library professional, partners and collaboration, location, themes and topics and types of programs. The many different types of programs listed during the word-by-word coding can be used as an example to explain the process of focused coding. The references related to the code node "type of program" are tested against the extensive body of data by conducting Word Searches and drawing connections between different categories and subcategories. Types of programs such as debates, concerts, film screenings, lectures and talks, literature events and group activities are listed as categories. Not surprisingly, many of these categories relate to the existing categories used in the annual national assessment reports. Looking at their subcategories, however, a broad range of programs are discovered, which extend the categories to which they belong and qualify the understanding of these. Adding to the complexity are subcategories, which seem to belong to more than one category. Examples of categories and subcategories are listed in Table 3 and relations to additional categories are indicated in brackets. 


\begin{tabular}{|l|l|}
\hline Category & Subcategory \\
\hline Debates & Conversation salons \\
\hline & Discussion groups (Group activities) \\
\hline & Debate cafés \\
\hline Concerts & Family concerts \\
\hline & Story time concerts (Literature events) \\
\hline & Musical lecture (Lectures and talks) \\
\hline Film screenings & Sleeping concert \\
\hline & Documentary film screenings \\
\hline & Film screening accompanied by live music (Concerts) \\
\hline Lectures and talks & Hangover movie event \\
\hline & Livestreaming of lectures \\
\hline & Live drawing and talk \\
\hline & Lecture or book talk by a writer (Literature events) \\
\hline & Book talks by librarian (Literature events) \\
\hline & Book talks by others (Literature events) \\
\hline Literature events & Reading sessions \\
\hline & Story time / Story telling \\
\hline & Writer meetings (Lectures and talks) \\
\hline & Reading by a writer \\
\hline Rroup activities & Discussion groups (Debates) \\
\hline & Reading circles (Literature event) \\
\hline & Knitting groups \\
\hline & Listening groups \\
\hline & of cating circles (Group activities) \\
\hline & \\
\hline &
\end{tabular}

Table 3. Examples of categories, subcategories and additional categories.

When it comes to types of programs, the listing of categories and subcategories are not sufficient to grasp the content and function of these. An example is the fact that several types of programs are belonging to more categories at the same time. These overlapping categories should be examined closer. Furthermore, the relationship between themes and topics and types of programs should be explored.

\section{Selective coding}

Selective coding is explained as the "process of selecting the core category, systematically relating it to other categories, validating those relationships, and filling in categories that need further refinement and development" (Strauss and Corbin, 1990: 116). The core category is the central phenomenon around which all other categories are combined (Strauss and Corbin, 1990). During the process of selective coding, a temporary list of categories, which seems key to public library programs, is created. This list is informed by the compiled memos and diagrams as well as the categories, properties and dimensional locations identified in the process of open coding. The key categories explored in the selective coding are: access, the role of the library professional, partnerships and collaboration and location. 
As already mentioned, access seems to be an important category in relation to public library programs, since it refers not only to the practical aspects of public library programs (such as entrance fees and registrations) but also to the deeply ideological aspects behind public library programs as public services, which should be equally available and accessible for all (LaFleur and Robotham, 1981). Another important category is the role of the library professionals. In this category, properties refer to how the role of the library professionals is expressed in the event descriptions and signals if a partnership or a collaboration is taking place. The dimensional locations are placed on a continuum from the library professionals acting as hosts in charge of the program to programs organized and conducted entirely by others (e.g. volunteers). The aspect of partnerships and collaboration present in this category is explored as a category of its own, in which properties refer to different types of partnerships and collaborations with external institutions and organizations as well as individuals and volunteers from the community. The dimensional locations concerns the degree of collaboration placed on a continuum from no collaboration with external agents to programs driven by volunteers. A subcategory to partnerships and collaboration is location, which is characterized by properties such as inside, outside or elsewhere. The dimensional locations are easy to place on a continuum from taking place within the public library to taking place within other institutions or organizations, outdoors or even far from the library, as is the case with arranged visits or trips. As a result of the selective coding, a list of different locations is created. Even though more than 30 different arenas appear in the data - including schools, churches, outdoor areas, museums, cafés and cultural houses - the majority of public library programs are held within public libraries.

What does it mean whether a program takes place within the library, outside of the library or within another institutions and organizations? And what characterizes the different types of "authorship" ascribed to the programs? These are complex questions, which come from the data. Since the aim of this paper is to report on a new approach for researching public library programs, these questions will not be answered for now. Instead, the final part of this paper will reflect on the utility of the research approach presented and discuss its challenges and possibilities.

\section{Summative discussion}

The research approach presented in this paper consists of three key elements: grounded theory as a research strategy, Facebook events as the primary sources of data and web archiving as a method for data collection. The relationships between these three elements, as well as their individual challenges and possibilities, are discussed in the following.

By experimenting with grounded theory in the study of Facebook events as extant texts, this paper presents a novel approach to the study of social media content using grounded theory. The distinction between extant texts and elicited texts proves to be useful in the categorization of textual social media content and memos and diagrams appear to be highly valuable analytical tools throughout the research processes. As a research strategy for acquiring qualitative insights into the concepts and categories used to describe public library programs announced on Facebook, the use of grounded theory is found valuable. The experimental take on grounded theory in combining coding procedures described by 
Strauss and Corbin $(1990 ; 2008)$ and Charmaz $(2006 ; 2014)$ is another contribution of this paper. The combination of initial- and open coding proves to be valuable for asking questions about the data and of the data and for discovering categories and subcategories relating to the different types of programs described. Thus, this approach has been useful for qualifying the understanding of the elements characterizing both the Facebook events and the public library programs announced in these events. In the combination of focused- and selective coding, the categories and subcategories found during the initial- and open coding of small samples of data are tested against the bigger body of data. In these processes, what seem to be key categories are explored by systematically relating them to the extensive data. The key categories explored are: access, the role of the library professional, partnerships and collaboration and location. All of these categories refer to general conditions, which characterizes the format of public library programs. More challenging to code are categories such as types of programs not to mention themes and topics. Both of these categories are characterized by a high level of complexity, since they refer to the content and possibly the function of public library programs.

This paper argues that Facebook events are useful, sufficient and suitable sources of data for a grounded theory study. Especially the Facebook event descriptions provide rich and detailed data, which is useful for developing core categories. The widespread use of Facebook amongst Danish public libraries as a platform for announcing programs and the large number of descriptive texts available online indicate the sufficiency of this type of data. Finally, the use of Facebook as a platform for announcing public library programs makes the descriptions of these programs more alike and increases the level of comparability, which make the texts more suitable to research.

The interrelatedness between data collection, data analysis and theory development characteristic of grounded theory becomes visible in the process of web archiving the Facebook content, considering what to collect and what to preserve.

"Data collection methods (...) necessarily delimit a very small portion of reality from which inferences and interpretations can be made. Importantly, collection and 'sampling' refer both to data that can be 'found' (e.g., online observations of internet communities) and data that can be 'made' (e.g., interviews with their administrators and other key members)" (Jensen, 2012: 442, original emphasis).

In the study of social media content such as Facebook events, the distinction between data as either found or made becomes insufficient (Jensen, 2012). Facebook events are found data in that respect they are found online and that the researchers have had no hand in shaping it. However, when collected by means of web archiving this data begin to reflect what the researchers have decided to collect, fixate and preserve. Further, in grounded theory research, memos, diagrams and code nodes are made by defining what is found in the data and believed to be important. This complicates the understanding of what is the original data. During the processes of web archiving, the memos written to reflect on the nature of the data collected and the value of the methods used are considered as findings as well. Therefore, as a method for collecting and preserving Facebook events and as a way 
to reflect on the data and its contexts, web archiving plays a crucial role in the research approach presented in this paper.

Summing up, the combination of grounded theory as a research strategy, Facebook events as data and web archiving as methods for data collection proves to be a promising new approach for researching the format, content and function of public library programs, thus, contributing to a more qualified understanding and conception of this phenomenon.

\section{Conclusion}

This paper reports on a promising new research approach for studying public library programs through Facebook events, using grounded theory as a research strategy and web archiving as methods for data collection. The result is a research approach that can be used not only for researching public library programs, but for qualitative analyses of institutional and organizational Facebook content in general and Facebook events and Facebook event descriptions in particular. However, further research is needed to make use of the full potential of this approach. Hopefully, the insights from this paper will serve as a foundation for future research on public library programs, since a qualified understanding and conception of this highly complex phenomenon is needed.

\section{Acknowledgements}

[Uploaded separately]

\section{References}

Afzalan, N. and Evans-Cowley, J. (2015). "Planning and Social Media: Facebook for Planning at the Neighbourhood Scale", Planning Practice \& Research, Vol. 30, No. 3, pp. 1-16.

Aharony, N. (2012). "Facebook use in libraries: an exploratory analysis", Aslib Proceedings, Vol. 64, No. 4, pp. 358372.

Audunson, R. (2005). "The public library as a meeting-place in a multicultural and digital context", Journal of Documentation, Vol. 61, No. 3, pp. 429-441.

Baguley, F.W.S. (1959). "Extension Activities in Public Libraries”, New Library World, Vol. 61, No. 4, pp. 77-100.

Brügger, N. (2005). Archiving websites, general considerations and strategies, The Center for Internet Research, Aarhus.

Brügger, N. (2011). "Web archiving-Between past, present, and future", in M. Consalvo and C. M. Ess (Eds.), The Handbook of Internet Studies, Wiley-Blackwell Oxford, UK, pp. 24-42.

Cahill, K. (2011). "Going social at Vancouver Public Library: what the virtual branch did next", Program, Vol. 45, No. 3, pp. 259-278.

Carlsson, H. (2015). "Researching Public Libraries and the Social Web, 2006-2012", Journal of Documentation, Vol. 71, No. 4, pp. 632-649.

Carpenter, S. and Lertpratchya, A.P. (2016). “A Qualitative and Quantitative Study of Social Media Communicators: An Extension of Role Theory to Digital Media Workers". Journal of Broadcasting \& Electronic Media, Vol. 60 , No. 3, pp. 448-464.

Charmaz, K. (2006). Constructing grounded theory, a practical guide through qualitative analysis, SAGE Publications, London.

Charmaz, K. (2014). Constructing Grounded Theory. Introducing qualitative methods, (2 ${ }^{\text {nd }}$ ed.), SAGE Publications, London. 
Chen, D.Y.T., Chu, S.K.W. and Xu, S.Q. (2012), "How do libraries use social networking sites to interact with users", Proceedings of the Association for Information Science and Technology, Vol. 49, No. 1, pp. 1-10.

Corbin, J. and Strauss, A. (2008). Basics of qualitative research, techniques and procedures for developing grounded theory (3erd ed.), SAGE Publications, Los Angeles and London.

Danish Agency for Culture and Palaces (2010). "Biblioteksbarometer", available at: https://slks.dk/fileadmin/user_upload/dokumenter/servicemenu/statistik/biblioteksstatistik/Biblioteksbarometer_ 2010.pdf (accessed 2 July 2018).

Danish Agency for Culture and Palaces (2015). "Biblioteksbarometer", available at: https://slks.dk/biblioteker/biblioteksstatistik/biblioteksbarometer-for-folkebiblioteker/ (accessed 2 July 2018).

Davies, D.W., (1974). Public Libraries as Culture and Social Centers: The Origin of the Concept. The Scarecrow Press, Inc., Metuchen, N.J.

Department of Education and Science (1975). Public libraries and cultural activities, Library Information Series, No. 5, Her Majesty's Stationery Office, London.

Faggiolani, C. (2011). "Perceived Identity: Applying Grounded Theory in Libraries", JLIS.it, Italian Journal of Library and Information Science, Vol. 2, No. 1, pp. 4592-590.

Goulding, A., Shuker, M. and Dickie, J. (2018). “Apps on laps: digital storytimes in public libraries in Aotearoa New Zealand”, Library Hi Tech, Vol. 36, No. 2, pp. 252-269.

Hedemark, A. (2017). “Telling Tales. An Observational Study of Storytelling for Children in Swedish Public Libraries", New Review of Children's Literature and Librarianship, Vol. 23, No. 2, pp. 106-125.

Hedemark, Å. and Lindberg, J. (2018). "Babies, Bodies, and Books_Librarians' Work for Early Literacy”, Library Trends, Vol. 66, No. 4, pp. 422-441.

Hofschire, L. and Wanucha, M. (2014). "Public Library Websites and Social Media", Computers in Libraries, Vol. 34, No. 8, pp. 4-9.

Johnston, J. (2018). "The use of conversation-based programming in public libraries to support integration in increasingly multiethnic societies", Journal of Librarianship and Information Science, Vol. 50, No. 2, pp. 130140.

Johnston, J. and Audunson, R. (2019). "Supporting immigrants' political integration through discussion and debate in public libraries", Journal of Librarianship and Information Science, Vol. 51, No. 1, pp. 228-242.

Jolliffe, H. (1962). Public library extension activities, Library Association, London.

Joo, S., Choi, N. and Baek, T.H. (2018). "Library marketing via social media". Online Information Review, Vol. 42, No. 6, pp. 940-955.

Jensen, K. B. (2012). "Lost, Found, and Made. Qualitative data in the Study of Three-Step Flows of Communication", in Volkmer, I. (Ed.), The Handbook of Global Media Research (1st ed.), Blackwell Publishing Ltd. Oxford, pp. 435-450.

Khan, Z., \& Jarvenpaa, S. L. (2010). "Exploring temporal coordination of events with facebook.com”, Journal of Information Technology, Vol. 25, No. 2, pp. 137-151.

LaFleur, L. and Robotham, J.S. (1976). Library programs, how to select, plan and produce them. Scarecrow press, Metuchen, N.J.

LaFleur, L. and Robotham, J.S. (1981). Library programs, how to select, plan and produce them, (2 ${ }^{\text {nd }}$ ed.), Scarecrow press, Metuchen, N.J.

Lenstra, N. (2018). “Let’s Move! Fitness Programming in Public Libraries”, Public Library Quarterly, Vol. 37, No. 1, pp. 61-80.

Lenstra, N. (2017). "Yoga at the Public Library: An Exploratory Survey of Canadian and American Librarians", Journal of Library Administration, Vol. 57, No. 7, pp. 758-775.

Leyland, E., 1938. The wider public library. Grafton \& company, London.

Lomborg, S. (2012). "Researching Communicative Practice: Web Archiving in Qualitative Social Media Research", Journal of Technology in Human Services, Vol. 30, No. 3-4, pp. 219-31.

Lopez, M., Caspe, E.M. and Simpson, C. (2017). "Engaging families in Public Libraries", Public Library Quarterly, Vol. 36, No. 4, pp. 318-333.

Luo, L. (2018). "Health information programming in public libraries: a content analysis", Public Library Quarterly, Vol. 37, No. 3, pp. 233-247.

National Impact of Library Public Programs Assessment (NILPPA) (2018). "What Is a Public Program, Anyway?", available at: https://nilppa.org/phase-1/what-is-a-public-program-anyway/ (accessed June 26th 2018).

New York Public Library (2018). "Events", available at: https://www.nypl.org/events/calendar (assessed June 6th 2018).

Nielsen, J. (2016). Using web archives in research - an introduction, NetLab, Aarhus.

Noh, Y. (2017). "A study of the effects of library creative zone programs on creative thinking abilities", Journal of Librarianship and Information Science, Vol. 49, No. 4, pp. 380-396. 
Madge, O.L. and Coserea, L. (2014), "The Facebook challenge for public libraries in Romania", Studii de Biblioteconomie şi Ştiinţa Informării, Vol. 18, pp. 89-93.

McColvin, L.R. (1927). Library extension work and publicity. Grafton, London.

Robards, B. and Lincoln, S. (2017). "Uncovering longitudinal life narratives: scrolling back on Facebook", Qualitative Research, Vol. 17, No. 6, pp.715-730.

Rockefeller, E. (2008). “STRIVING TO SERVE Diverse Youth”, Public Libraries, Vol. 47, No. 1, pp. 50-55.

Rubenstein, E. (2016). "Breaking health barriers: How can public libraries contribute?", Public Library Quarterly, Vol. 35, No. 4, pp. 331-37.

Sandvik, K., Brügger, N. and Laursen, D. (2013). "Method for collecting facebook data and their effects on later analysis", paper presented at NORDMEDIA conference, Oslo, Norway.

Silver, A. and Matthews, L. (2017). "The use of Facebook for information seeking, decision support, and selforganization following a significant disaster", Information, Communication \& Society, Vol. 20, No. 11, pp. 1680-1697.

Strauss, A. and Corbin, J. (1990). Basics of Qualitative Research, Grounded Theory, Procedures and Techniques, Sage Publications, Newbury Park.

Smith, H.L., 1954. Adult education activities in public libraries. ALA, Chicago.

Stevenson, G.T. (1963). "Library Adult Education Activities in Public Libraries of Germany, Denmark, and England", ALA Bulletin, Vol. 57, pp. 643-654.

Sydney, E., Thomsen, C. and Tomkins, M.D. (1950). Adult education activities for public libraries, Unesco Public Library Manuals 3. Unesco, Paris.

Teddlie, C. and Yu, F. (2007). "Mixed Methods Sampling: A Typology With Examples", Journal of Mixed Methods Research, Vol. 1, No. 1, pp. 77-100.

Thorsen, L. (1992). De danske folkebiblioteker 1940-1983, Dansk Biblioteks Center, Ballerup.

Tomlin, M. (2014), "Using Facebook to market libraries", in Thomsett-Scott, B.C. (Ed.), Marketing with Social Media: A LITA guide, American Library Association, Chicago, IL, pp. 25-38.

Vårheim, A. (2014). "Trust and the role of the public library in the integration of refugees: The case of a Northern Norwegian city", Journal of Librarianship and Information Science, Vol. 46, No. 1, pp. 62-69.

\section{Notes}

\footnotetext{
${ }^{1}$ noegletal.dk

${ }^{2}$ https://www.techsmith.com/screen-capture.html

${ }^{3} \mathrm{https}: / /$ developers.facebook.com/docs/graph-api

${ }^{4}$ https://developers.facebook.com/docs/graph-api/overview/

${ }^{5}$ The Facebook data was collected in February, 2018.

${ }^{6} \mathrm{https}: / /$ www.tableau.com/
} 